\title{
ANTI-CONVULSANT ACTIVITY OF GANAXOLONE ALONE AND IN COMPARISON WITH STANDARD ANTI-EPILEPTIC DRUGS IN RODENT MODELS
}

Mr. S.K. Subhani Basha, Dr .B. L. Kudagi, Dr. R. Pravin Kumar

1. Tutor, Department of Pharmacology, Narayana Medical College, Nellore.

2. Professor \& H.O.D., Department of Pharmacology, Narayana Medical College, Nellore.

3. PG Student, Department of Pharmacology, Narayana Medical College, Nellore.

\section{CORRESPONDING AUTHOR:}

Dr.B. L. Kudagi,

Professor \& H.O.D.,

Department of Pharmacology,

Narayana Medical College,

Nellore.

Email ID-blkudagi@rediffmail.com

\section{ABSTRACT:}

BACKGROUND: Presently, treatment of epilepsy with standard anti-epileptic drugs is associated with a number of shortcomings inviting us to study newer agents that would overcome these problems or search for the drugs or substances, which would enhance the efficacy or reduce the dose or toxicity of these standard anti-epileptic drugs. Ganaxolone (GNX) ( $3 \alpha$-hydroxy-3 $\beta$-methyl-5 $\alpha$-pregnan-20-one), a synthetic analog of the endogenous neurosteroid allopregnanolone and a positive allosteric modulator of $\mathrm{GABA}_{\mathrm{A}}$ receptors, may represent a new treatment approach for epilepsy. AIM: To evaluate the effect of Ganaxolone on maximal electroshock (MES) induced and Pentylenetetrazol (PTZ) induced convulsions and also their effect in combination with conventional antiepileptic drugs (CAEDs). MATERIAL AND METHODS: Wister strain albino rats weighing 200-250 gm were used. Effects of Ganaxolone ( $5 \& 10 \mathrm{mg} / \mathrm{kg}$ ) alone and in combination with standard drugs were studied in MES and PTZ induced seizure models. Abolition of tonic hind limb extension was an index of anticonvulsant activity in MES, while for PTZ seizures; failure to observe clonus for $5 \mathrm{sec}$ duration for $30 \mathrm{~min}$ was the index. Following that, percentage inhibition was calculated. STATISTICS: ANOVA followed by Newman-Keuls Multiple Comparison Test was used for analysis of data between the groups. RESULTS: In MES seizures, significant antiepileptic activity was observed with $10 \mathrm{mg}$ of Ganaxolone compared to control group but has less activity when compared to that of Phenobarbitone. In PTZ induced convulsions, the anti-epileptic effect of Sodium Valproate was higher than Ganaxolone, but both were statistically significant as compared to control. In PTZ-induced seizures, augmented effects were obtained when Ganaxolone was combined with sodium valproate i.e. 55\%. CONCLUSIONS: The results provide a lead for potential benefit of adding Ganaxolone to Sodium Valproate in the treatment of epilepsy, which needs to be explored further.

KEYWORDS: Seizures, Ganaxolone, Phenobarbitone, Sodium Valproate, Pentylenetetrazol, Hydoxypropyl- $\beta$-Cyclodextrin, GABA. 


\section{INTRODUCTION:}

Epilepsy is a common and chronic neurological disorder characterized by apparently unprovoked recurrent paroxysmal events or seizures that are associated with a sudden alteration in motor activity and behavior, with or without alteration in conscious awareness. The alteration in state is the result of an abnormal and excessive hyper synchronous firing within a group of epileptic neurons in the brain ${ }^{1}$. Epilepsy affects around 50 million people worldwide and the majority of people with epilepsy (70\%) have a good prognosis if they receive appropriate treatment. The prevalence of active epilepsy is roughly in the range of 5-10 per 1000 people $^{2}$. Epilepsy's approximate annual incidence rate is $40-70$ per 100,000 in industrialized countries and $100-190$ per 100,000 in resource-poor countries; socioeconomically deprived people are at higher risk. In industrialized countries the incidence rate decreased in children but increased among the elderly during the three decades prior to 2003, for reasons not fully understood. Epilepsy's lifetime prevalence is relatively high because most patients either stop having anti-epileptic drugs or (less commonly) die ${ }^{3}$.

In about two-thirds of all patients affected with epilepsy, seizures are well controlled with currently available anti-epileptic drugs, while in the remainder seizures are refractory to treatment. Moreover, many of the existent anti-epileptic agents produce many undesirable side-effects including drowsiness, mental dullness, nausea, ataxia, paresthesia, hematologic changes, hirsutism, weight gain, hypertrophy of gums and congenital malformations. For these reasons, new antiepileptic drugs are needed to improve seizure control and decrease side-effect profile ${ }^{4}$.

At the neuronal level, seizure activity often occurs when glutamatergic excitatory neurotransmission overrides GABA-mediated inhibition. Therefore, glutamatergic and GABAergic systems are rational targets for antiepileptic drug development ${ }^{5}$. Pharmacological manipulations leading to increased levels of GABA (by inhibition of GABA degradation or reuptake) and/or positive allosteric modulation of the GABA receptor complex are among the approaches that have been used to facilitate inhibitory GABAergic neurotransmission'.

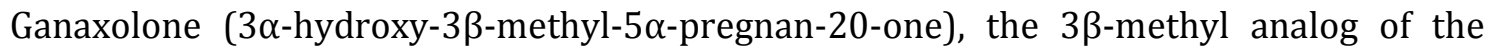
progesterone metabolite allopregnanolone, is the first synthetic neurosteroid related agent to be evaluated in man for the drug treatment of epilepsy, which is now undergoing phaseIII clinical trials ${ }^{7}$. Ganaxolone, like Allopregnanolone, acts as a powerful positive allosteric modulator of $\mathrm{GABA}_{\mathrm{A}}$ receptors, resulting in enhanced neural inhibition ${ }^{8}$.

Hence, the present study was undertaken to determine whether Ganaxolone alone or along with standard antiepileptic drugs could provide superior seizure control in maximal electroshock (MES) induced and Pentylenetetrazol (PTZ) induced convulsions as compared to CAEDs.

\section{MATERIALS \& METHODS:}

ANIMALS:

Wister strain albino rats weighing between 200-250gms were used, for this study. The animals were obtained from the central animal house of Narayana Medical College, 
Nellore. They were housed in standard polypropylene cages. The animals were excluded if the weight of rats were below 200gms and if they had any visible diseases. The animals are maintained under standard laboratory conditions $(12: 12 \mathrm{hr}$ light: dark cycles and temperature $25^{\circ} \mathrm{C} \pm 1^{\circ} \mathrm{C}$ with free access to food and water ad libitum. All the experiments were carried out around the same time each day. All the experimental procedures and protocols were reviewed and approved by the Institutional Animal Ethics Committee (IAEC) of the institute, with protocol number 12/2010/NMC.

\section{CHEMICALS \& DRUGS:}

All standard chemicals used in this study were of analytical grade. Pure form of Ganaxolone \& Hydoxypropyl- $\beta$-Cyclodextrin were obtained from Sigma chemicals. Stock solutions of Ganaxolone for injection were made in $40 \%$ Hydoxypropyl- $\beta$-Cyclodextrin in water. By itself, $\beta$-cyclodextrin at concentrations as high as $50 \%$ failed to affect seizures.

\section{ASSESSMENT OF ANTICONVULSANT ACTIVITY: GROUPING:}

To study the anti-epileptic activity of Ganaxolone, two models namely MES induced convulsions and Pentylenetetrazol induced convulsions in rats were used. Each model consists of five groups, each group containing 6 animals.

Groups were divided as follows,

Group I (Control group) was treated with 40\% (w/v) Hydoxypropyl- $\beta$-Cyclodextrin 4ml/kg body weight.

Group II received Ganaxolone at a dose of $5 \mathrm{mg} / \mathrm{kg}$ body weight.

Group III received Ganaxolone at a dose of $10 \mathrm{mg} / \mathrm{kg}$ body weight.

Group IV received standard drug (Phenobarbitone 20mg/kg - MES, Sodium Valproate 200mg/kg - PTZ seizures).

Group V received Ganaxolone at $5 \mathrm{mg} / \mathrm{kg}$ body weight and standard drug.

Separate groups of animals were used for different models and all the groups received the drugs intraperitonially at different sites throughout the experiment. Concentration of drugs were so adjusted that all the animals in the group received the same volume of preparation throughout the study. All the drugs were given 30 min prior to the induction of convulsions.

\section{MES SEIZURE METHOD 9 :}

Anticonvulsant activity of Ganaxolone was tested for MES seizure by inducing convulsions with an electroconvulsiometer. In this method, electrical stimulation was applied via clipped-ear electrodes (moistened with saline solution before each application) which delivered a constant current of $150 \mathrm{~mA}$ current for 0.2 seconds. Abolition of hind limb tonic extension was taken as an index of anticonvulsant activity ${ }^{10}$. Parameters observed were time for onset and duration of tonic hind limb extension (THE).

\section{CHEMICALLY INDUCED SEIZURES 9 :}


Pentylenetetrazol is a tetrazol derivative with consistent convulsive effect in a larger number of animal species like mice, rats, cats, primates etc. It is believed to act by antagonizing the inhibitory GABAergic neurotransmission10. This model was used to screen the anti-epileptic efficacy of Ganaxolone against petit mal epilepsy as Ganaxolone also acts through $\mathrm{GABA}_{-\mathrm{A}}$ receptor modulator mechanism.

Rats were injected with Pentylenetetrazol (70 mg/kg, i.p) 30 minutes after test drug and standard drug (Sodium Valproate - 200mg/kg) and the occurrence of the first generalized clonus (repeated clonic seizures of the fore and hind limb lasting over 5sec. with an accompanying loss of righting reflex) or jerky movements were recorded during individual observation for $30 \mathrm{~min}$.

\section{STATISTICAL ANALYSIS:}

The data was collected in case record forms and then entered into excel spreadsheet 2007. Statistical analysis was performed using Microsoft Excel - 2007 and Sigma Graph pad prism version-5 USA. Data was described as Mean \pm Standard deviation. One way ANOVA followed by Newman-Keuls Multiple Comparison Test was used for analysis of data between the five groups. For all inferential statistical tests a two tailed $\mathrm{P}$ value of less than 0.05 was considered significant.

\section{RESULTS:}

\section{EFFECT OF GANAXOLONE ON TONIC HIND LIMB EXTENSION IN MES:}

Tonic hind limb extension was completely abolished in group IV (treated with Phenobarbitone) and group V (combination of Ganaxolone and Phenobarbitone). Percentage inhibition of duration of tonic hind limb extension increased with the use of Ganaxolone $10 \mathrm{mg} / \mathrm{kg}$ up to $50 \%$ and were $100 \%$ for group IV and V. MES induced convulsions blocking activity of Ganaxolone $10 \mathrm{mg} / \mathrm{kg}$ was extremely significant $(\mathrm{p}<0.001)$ when compared to that of control but it was less effective when compared to Phenobarbitone. The combination of Ganaxolone + Phenobarbitone has a similar / superior MES induced convulsions blocking activity compared to that of Phenobarbitone alone.

\section{EFFECT OF GANAXOLONE ON PTZ INDUCED SEIZURES:}

The onset of jerky movements in PTZ induced convulsions were significantly delayed by Ganaxolone $10 \mathrm{mg} / \mathrm{kg} \quad(\mathrm{p}<0.001)$ as compared to the control. Percentage inhibition of duration of jerky movements with $10 \mathrm{mg}$ of Ganaxolone was $37.5 \%$ and it was $45 \%$ for sodium valproate, whereas as the combination of Ganaxolone + Sodium Valproate (group V) further decreased the duration of jerky movements up to 55\%, implying that PTZ induced convulsions blocking activity of Sodium Valproate was more than that of Ganaxolone, but both were statistically significant. The combination of Ganaxolone and Sodium Valproate has a superior PTZ induced convulsions blocking activity compared to that of Sodium Valproate alone.

\section{DISCUSSION:}

Journal of Evolution of Medical and Dental Sciences/ Volume 1/ Issue 3/ July- Sept 2012 Page 113 
The present study was aimed at evaluating the effect of Ganaxolone on maximal electroshock (MES) induced and Pentylenetetrazol (PTZ) induced convulsions and also their effect in combination with conventional antiepileptic drugs (CAEDs) using animal models.

Ganaxolone (GNX) is the synthetic analog of allopregnanolone $(3 \alpha, 5 \alpha-\mathrm{P})$ it belongs to a class of compounds referred to as neurosteroids that have been termed "epalons" which has been presumed to possess sedative, anxiolytic, and anticonvulsant effects ${ }^{11}$.

Maximal electric shock induced convulsions is a suitable test for evaluating antiepileptic properties of drugs, because it is the best-validated preclinical test that predicts drugs effective against generalized seizures of the tonic-clonic (grand mal) type.

In our study, we demonstrated significant anti-epileptic activity with $10 \mathrm{mg}$ of Ganaxolone compared to control group but has less activity when compared to that of Phenobarbitone but both were statistically significant. Using this model, Virinder Nohria et al. (2007) reported that, although Ganaxolone effectively blocked tonic seizures induced by maximal electroshock in mice (ED50 of $29.7 \mathrm{mg} / \mathrm{kg}$, i.p.), it did so at doses that produced ataxia on the rotorod (mean toxic dose, TD50, of $33.4 \mathrm{mg} / \mathrm{kg}$, i.p.) ${ }^{12}$. Same results were observed by Richard B. Carter et al (1997), who also reported that Ganaxolone was less potent against MES (ED50 of $29.7 \mathrm{mg} / \mathrm{kg}$ i.p.) than sodium valproate, resulting in protective indices of 1.1 , as opposed to 1.9 for valproate ${ }^{9}$.

We also evaluated the anti-epileptic activity of Ganaxolone using Pentylenetetrazol induced convulsions model, as this test is used for screening of drugs effective in petit mal epilepsy or absence seizures. By analyzing our results we like to state that PTZ induced convulsions blocking activity of Ganaxolone was slightly less than that of Sodium Valproate.

Our study was supported my Richard B. Carter et al (1997), who also reported that Ganaxolone produced potent anticonvulsant effects with PTZ induced convulsions, with an i.p. ED50 of $4.3 \mathrm{mg} / \mathrm{kg}$ in mice and $7.8 \mathrm{mg} / \mathrm{kg}$ in rats. Ganaxolone was also active after oral administration in rats, with an ED50 of $21.0 \mathrm{mg} / \mathrm{kg}$. The profile of anticonvulsant activity obtained for Ganaxolone is similar in many respects to that of the clinically used reference agent valproate. Ganaxolone is superior to valproate, however, in its ability to increase the seizure threshold for i.v. PTZ infusion at nonataxic doses 9 .

Also, Marjolein Beekman et al (1998) concluded that the neuroactive steroid Ganaxolone is superior to a host of standard antiepileptic agents (Diazepam, Clonazepam, Valproic acid, Ethosuximide, Phenobarbitone) in controlling the behavioral disturbances that result from both acute PTZ administration and a regimen of PTZ that induces seizure kindling. Although much less potent than Ganaxolone, Phenobarbital was the drug that most closely mirrored Ganaxolone in its anti-PTZ effects ${ }^{13}$.

Furthermore, Virinder Nohria et al (2007) also reported that Ganaxolone was effective against clonic convulsions induced by subcutaneous Pentylenetetrazol administration in mice and rats (ED50 values of 4.3 and $7.8 \mathrm{mg} / \mathrm{kg}$ i.p., respectively). He also stated that PTZ-induced seizures in rats did not develop tolerance to chronic treatment with Ganaxolone ${ }^{12}$.

MES-induced tonic extension can be blocked by drugs that inhibit voltage dependent $\mathrm{Na}^{+}$channels, such as phenytoin, carbamazepine, and valproate (Macdonald and Kelly,1995; 
Rogawski and Porter, 1990; White, 1997), as well as by drugs that block glutamatergic excitation mediated by the N-methyl-D-aspartate receptor, such as felbamate (McCabeet al., 1993; Subramaniam et al., 1995; White et al., 1995). In contrast, clonic seizures induced by PTZ can be blocked by drugs that reduce T-type $\mathrm{Ca}^{++}$currents, such as ethosuximide (Coulter et al., 1989), and drugs that enhance GABA $_{-A}$ receptor mediated inhibitory neurotransmission, such as benzodiazepines, phenobarbital and perhaps valproate and felbamate (Macdonald and Kelly, 1995; Rogawski and Porter, 1990; White, 1997) ${ }^{9}$.

Ganaxolone exhibits anticonvulsant activity to PTZ and to a lesser extent against MES induced convulsions. Ganaxolone increased the seizure threshold before attaining a dose sufficient to produce ataxia on the rota rod. The ability of Ganaxolone to both elevate seizure threshold and block i.p. PTZ induced seizures can be attributed to its modulatory effect on GABA-A neurotransmission. Whether this effect contributes to its ability to block MES induced tonic extension is not known, but that is likely, because there is at present no experimental evidence to suggest that Ganaxolone blocks voltage-dependent $\mathrm{Na}^{+}$channels or N-methyl-D-aspartate receptors.

Ganaxolone inhibits binding of the GABA-A $_{-A}$ chloride channel ligand and enhanced binding of the benzodiazepine site ligand and the GABA site ligand. Electrophysiological recordings showed that nanomolar concentrations of GNX potentiated GABA-evoked chloride currents in Xenopus oocytes expressing human GABA-A receptor subunits $\alpha 1, \beta 2, \gamma 2 \mathrm{~L}$, but direct activation of chloride flux occurred only at micromolar concentrations ${ }^{14,15}$.

The unique potency and efficacy of Ganaxolone against PTZ induced convulsions have several implications. First, these anti-epileptic effects of Ganaxolone in PTZ induced convulsions appear to be predictive of the potency and efficacy of Ganaxolone against absence seizures as it compares favorably with that of valproate. The results provide a lead for potential benefit of adding Ganaxolone to Sodium Valproate in the treatment of epilepsy, which needs to be explored further. Second, Ganaxolone may provide additional benefit in the treatment of epilepsy by controlling anxiety, mood changes and other behavioral alterations associated with preseizure activity. Finally, Ganaxolone may represent a novel treatment approach to the clinical control of epilepsy.

\section{CONCLUSION:}

Overall, Ganaxolone is a high-affinity, stereo selective, positive allosteric modulator of

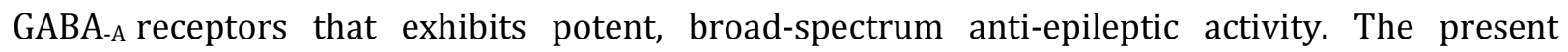
study supports clinical evaluation of Ganaxolone as an anti-epileptic medication with potential therapeutic utility in the treatment of generalized, absence seizures as well as simple and complex partial seizures, alone or as an add on drug with the conventional antiepileptic drugs to reduce their dose / adverse effects.

\section{ACKNOWLEDGEMENTS:}

The authors are thankful to the staffs and PGs of Narayana Medical College, Nellore and Sigma Aldrich.

Journal of Evolution of Medical and Dental Sciences/ Volume 1/ Issue 3/ July- Sept 2012 Page 115 
Table 1: Antiepileptic effect of Ganaxolone alone and in combination with Phenobarbitone on Maximal Electric Shock (MES) induced seizures in rats

\begin{tabular}{|c|c|c|c|c|}
\hline S.No & $\begin{array}{l}\text { Group \& Dose } \\
\text { (mg/kg i.p ) }\end{array}$ & $\begin{array}{l}\text { Mean time for } \\
\text { onset of THE } \\
\text { in secs }\end{array}$ & $\begin{array}{l}\text { Mean time duration of } \\
\text { THE in secs. }\end{array}$ & $\begin{array}{l}\text { Percentage } \\
\text { inhibition of } \\
\text { duration of THE }\end{array}$ \\
\hline 1. & Control & $2.7 \pm 0.52$ & $7 \pm 0.63$ & ---- \\
\hline 2. & Phenobarbitone - 20 & $0 * *$ & $0^{* *}$ & 100 \\
\hline 3. & Ganaxolone - 5 & $3.5 \pm 0.55^{*}$ & $6 \pm 0.89^{*}$ & 14.29 \\
\hline 4. & Ganaxolone - 10 & $6 \pm 0.63^{* *}$ & $3.5 \pm 0.55^{* *}$ & 50 \\
\hline 5. & $\begin{array}{lrr}\text { Ganaxolone } & 5 & + \\
\text { Phenobarbitone } & -10 & \end{array}$ & $0^{* *}$ & $0^{* *}$ & 100 \\
\hline
\end{tabular}

Table 2: Antiepileptic effect Ganaxolone alone and in combination with Sodium Valproate on PTZ induced seizures in rats

\begin{tabular}{|l|l|l|l|l|}
\hline $\begin{array}{l}\mathrm{S} . \\
\mathrm{N} \\
\mathrm{o}\end{array}$ & $\begin{array}{l}\text { Group \& Dose } \\
\text { (mg/kg bw ) }\end{array}$ & $\begin{array}{l}\text { Onset of mean time } \\
\text { for jerky movements } \\
\text { in min. }\end{array}$ & $\begin{array}{l}\text { Mean time } \\
\text { duration of jerky } \\
\text { movements in min. }\end{array}$ & $\begin{array}{l}\text { Percentage } \\
\text { inhibition of } \\
\text { duration of jerky } \\
\text { movements }\end{array}$ \\
\hline 1. & Control & $1.8 \pm 0.34$ & $40 \pm 4.1$ & ----- \\
\hline 2. & Sodium Valproate -200 & $8.9 \pm 1.3^{* *}$ & $22 \pm 1.8^{* *}$ & 45 \\
\hline 3. & Ganaxolone - 5 & $4.4 \pm 0.86^{* *}$ & $33 \pm 1.2^{* *}$ & 17.5 \\
\hline 4. & Ganaxolone - 10 & $7.8 \pm 0.88^{* *}$ & $25 \pm 1.5^{* *}$ & 37.5 \\
\hline 5. & $\begin{array}{l}\text { Ganaxolone } 5+ \\
\text { Sodium Valproate }-200\end{array}$ & $9.5 \pm 0.7^{* *}$ & 55 \\
\hline$* * 1.2^{* *}$ & \\
\hline
\end{tabular}




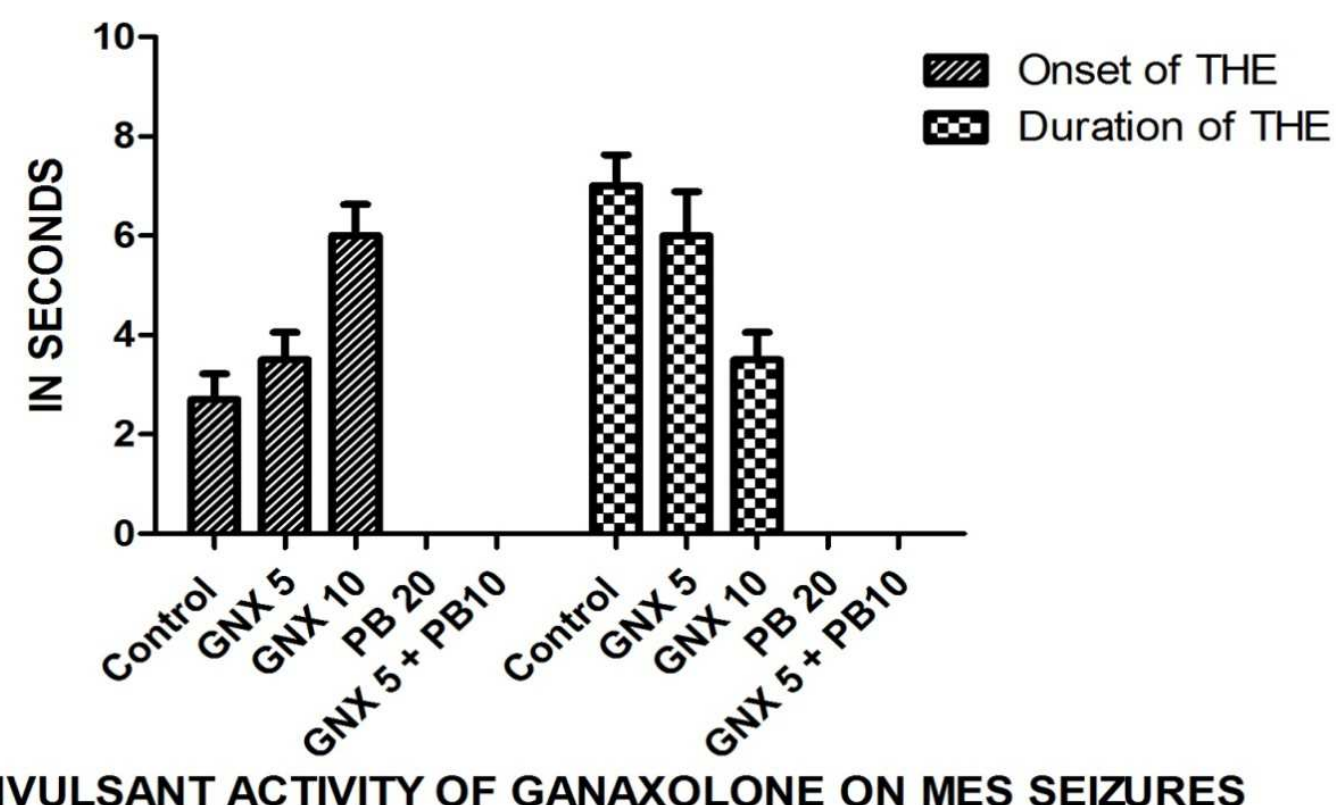

ANTICONVULSANT ACTIVITY OF GANAXOLONE ON MES SEIZURES

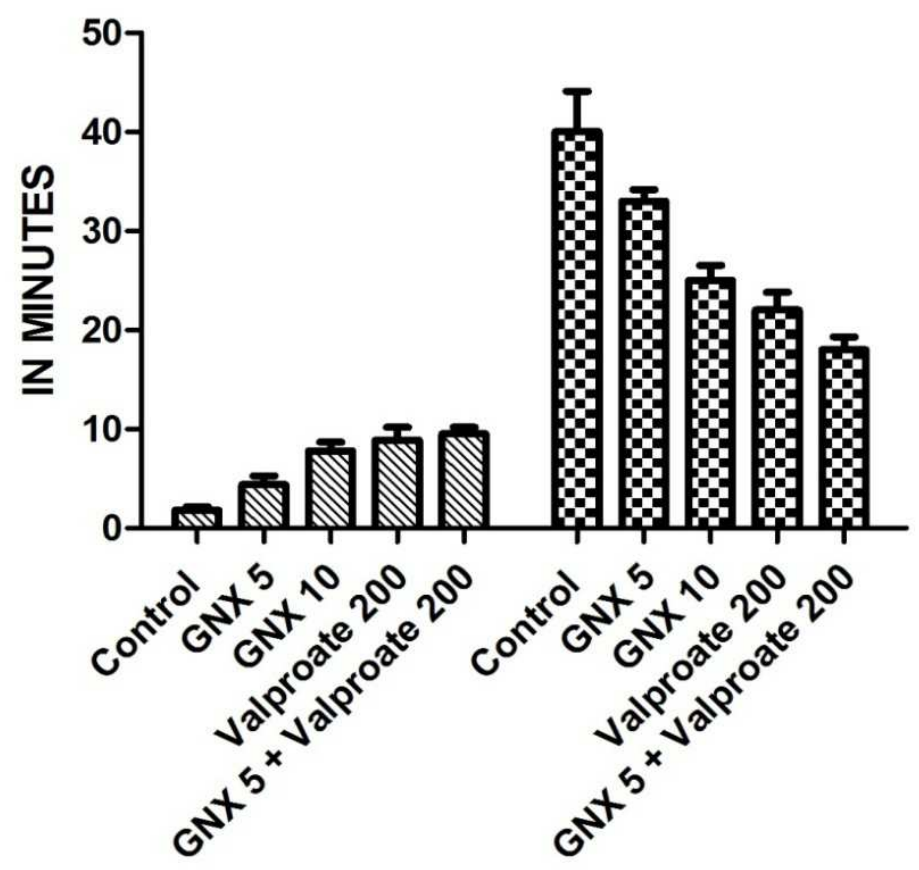

Onset of jerky movements

Dex Duration of jerky movements

\section{ANTICONVULSANT ACTIVITY OF GANAXOLONE ON PTZ SEIZURES}




\section{REFERENCES:}

1. Fisher RS, Van Emde Boas W, Blume W, et al. Epileptic seizures and epilepsy: definitions proposed by the International League Against Epilepsy (ILAE) and the International Bureau for Epilepsy (IBE). Epilepsia 2005;46(4):470-2.

2. "Epilepsy". World Health Organization. January 2009. Retrieved January 5, 2012.

3. Sander JW. The epidemiology of epilepsy revisited. Curr Opin Neurol 2003; 16: 165-70.

4. Maciej Gasior, Richard B Carter, Steven R Goldberg, Jeffrey M Witkin. Anticonvulsant and behavioral effects of neuroactive steroids alone and in conjunction with Diazepam. J Pharmacol Exp Ther 1997; 282: 543-553.

5. Bradford H F. Glutamate, GABA and epilepsy. Progress in Neurobiol 1995; 47:477-511.

6. Macdonald R L, Olsen RW. GABA A receptor channels. Annu. Rev. Neurosci. 1994; 17: 569-602.

7. Nohria V, Giller E. Ganaxolone. Neurotherapeutics 2007;4:102-105.

8. Rogawski MA, Reddy DS. Neurosteroids: endogenous modulators of seizure susceptibility. In: Rho JM, Sankar R, Cavazos JE, editors. Epilepsy: scientific foundations of clinical practice. New York: Marcel Dekker; 2004. P.319-355.

9. Carter RB, Wood PL, Wieland S, Hawkinson JE, Belelli D, Lambert JJ, et al. Characterization of the anticonvulsant properties of Ganaxolone (CCD 1042; 3-alphahydroxy-3-beta-methyl-5-alpha-pregnan-20-one), a selective, high-affinity, steroid modulator of the gamma-aminobutyric acid (A) receptor. J Pharmacol Exp Ther 1997;280:1284-95.

10. Mittal R. Antiepileptics. In: Gupta SK, editor. Drug Screening Methods. $1^{\text {st }}$ ed. New Delhi: Jaypee Brothers Medical Publishers; 2009. P. 408-9.

11. Gee K.W. Epalons as anticonvulsants: actions mediated by the GABA-A receptor complex. Proc West Pharmacol Soc 1996; 39: 55-60.

12. Virinder Nohria, Earl Griller. Ganaxolone. Neurotherpeutics: The Journal of the American society for Experimental Neurotherpeutics 2007; 4(1): 102-5.

13. Marjolein Beekman, Jesse T Ungard, Maciej Gasior, Richard B Carter, Durk Dijkstra, Steven R Goldberg, et al. Reversal of behavioral effects of Pentylenetetrazol by the Neuroactive Steroid Ganaxolone. JPET 1998; 284(3): 868-77.

14. Liptakova S, Velisek L, Veliskova J, Moshe SL. Effect of Ganaxolone on flurothyl seizures in developing rats. Epilepsia 2000; 41:788-93.

15. Kaminski RM, Livingood MR, Rogawski MA. Allopregnanolone analogs that positively modulate GABA receptors protect against partial seizures induced by $6-\mathrm{Hz}$ electrical stimulation in mice. Epilepsia 2004; 45: 864-67. 